\title{
Decision Optimization for Cold Chain Logistics of Fresh Agricultural Products under the Perspective of Cost-Benefit
}

\author{
Ying Ji \\ Shanghai University, Shanghai, China \\ Email: 694841924@qq.com
}

How to cite this paper: Ji, Y. (2019) Decision Optimization for Cold Chain Logistics of Fresh Agricultural Products under the Perspective of Cost-Benefit. Open Access Library Journal, 6: e5232. https://doi.org/10.4236/oalib.1105232

Received: February 11, 2019

Accepted: February 24, 2019

Published: February 27, 2019

Copyright $\odot 2019$ by author(s) and Open Access Library Inc.

This work is licensed under the Creative Commons Attribution International License (CC BY 4.0).

http://creativecommons.org/licenses/by/4.0/

\section{(c) () Open Access}

\begin{abstract}
In recent years, the production of fresh agricultural products (FAPs) in our country has been increasing rapidly, but FAPs are badly depleted in circulation. Then strengthening the construction of cold chain logistics and improving logistics efficiency have become a problem that needs to be solved. This paper studied the decision-making optimization and using the analytical model to the cold chain logistics of FAPs from the perspective of the cost-benefit. Through using numerical analysis, it proves the scientific nature of adopting the Internet of Things technology in practice, which is a cold chain for fresh produce and also provides the fresh agricultural enterprises to provide a theoretical basis for enterprises to invest in Internet technology, which has important application value in improving the efficiency of cold chain logistics of FAPs.
\end{abstract}

\section{Subject Areas \\ Supply Chain Management}

\section{Keywords}

Fresh Agricultural Products, Cold Chain Logistics, Interne of Things

\section{Introduction}

Cold chain logistics is a special form of logistics activities, including primary vegetables, fruits, meat, poultry, eggs, aquatic products, flowers and other primary agricultural products; frozen food, poultry, meat, aquatic products and other packaged cooked food; ice cream and processed foods such as dairy products, chocolates, and snack foods; medicines, etc. Fresh Agricultural Products 
(FAPs) refer to agricultural products that are grown or cultivated, processed or processed only for human consumption. The main types are fruits (fruits), vegetables, livestock and so on. Most of them are perishable and perishable products, which cannot be stored for a long time and require high storage conditions. However, the development of cold chain logistics of fresh agricultural products in China is seriously lagging behind. According to statistics, about 400 million tons of fresh agricultural products enter the circulation field every year. About $90 \%$ of the meat, $80 \%$ of the aquatic products, and $95 \%$ of the fruits and vegetables are sold without the guarantee of cold chain. The loss of fresh agricultural products is more serious, including meat consumption loss rate of $12 \%$, aquatic products up to $15 \%$ and fruits and vegetables up to $20 \%$ to $30 \%$; the annual loss amount of only fruits and vegetables are more than 100 billion yuan, and the high logistics loss is intensified. The quality and safety risks of agricultural products have pushed up the prices of agricultural products.

Therefore, with the continuous growth of demand for fresh agricultural products and the high loss of logistics in recent years, the development of cold chain logistics of fresh agricultural products has also received extensive attention from scholars at home and abroad. Some scholars used mathematical analysis methods to discuss the cold chain logistics temperature control, cold chain performance optimization, and cold chain transportation vehicle scheduling of fresh produce. In order to improve the informationization of cold chain logistics, reduce the information asymmetry of circulation links at all levels, and make some contribution to the application of some information technology such as logistics network technology to cold chain logistics [1] [2] [3] [4] [5], some scholars explored the use of radio frequency technology to optimize the location tracking of fresh agricultural products and the informationization of transportation, warehousing, distribution processing, etc., and strengthen the communication of all links in the cold chain to achieve cold chain agricultural products. Real-time monitoring and traceability further confirms that RFID adoption will improve the efficiency of cold chain logistics [6] [7] [8] [9] [10]. However, the adoption of the Internet of Things technology in the cold chain logistics of fresh agricultural products will inevitably increase the operating costs of the circulation entities at all levels. Some scholars constructed a cold chain logistics system framework for fresh agricultural products including multiple IoT systems and information platforms. The operating mechanism of the system was analyzed from the perspective of the cold chain logistics process of fresh produce, and the Internet of Things was studied. Adopting the two stages before and after, the various costs and benefits of the upstream and downstream of the supply chain, focusing on the impact of the adoption of the Internet of Things on the upstream and downstream wholesale prices, retail prices and order quantity decisions, and the cold chain logistics with fresh agricultural products are important boundary values that are closely related to revenue decisions [11] [12] [13] [14].

This paper comprehensively analyzes the adoption of IoT technology in the cold chain logistics of fresh produce from the perspective of the total cost and 
benefit of the entire cold chain logistics. Section 1 describes the background of this research and the research status at home and abroad, which lays the foundation for the follow-up research. Section 2 describes the decision-making optimization of cold chain logistics of fresh produce. Section 3 establishes the logistics decision-making optimization model of adopting the Internet of Things technology in the cold chain logistics of fresh produce. Section 4 optimizes the proportion of the cost of adoption of IoT by wholesalers and retailers through numerical analysis, so that the total revenue of the whole cold chain logistics is the largest, which provides a theoretical basis for the investment of IoT technology for fresh-chain agricultural cold chain enterprises. The application of the cold chain logistics of the whole fresh produce provides important application value. Section 5 provides the direction for subsequent research on the basis of summarizing the research.

\section{Decision-Making Optimization of Cold Chain Logistics for Fresh Produce}

\subsection{Problem Description}

After adopting the Internet of Things technology, the cold chain logistics of fresh agricultural products will greatly improve the circulation time, circulation efficiency, product loss, product quality, etc., transportation costs, storage costs, wholesale prices, retail prices, and retail prices for retailers and wholesalers. Order quantities and total supply chain costs also have a significant positive impact. However, after adopting the Internet of Things technology, certain IoT adoption costs will be generated. This paper will analyze the wholesaler and retailer two-level supply chain entities to determine where to pay their expenses to maximize the total supply chain revenue. For wholesalers, transportation costs, storage costs, product costs, product losses, technology costs, etc. have a direct impact on them; for retailers, technical costs, storage costs, circulation costs, transportation costs, product losses, etc. It has a direct impact. Figure 1 shows the one-way process of the fresh produce supply chain.

\subsection{Symbolic Expression}

1) Parameter

\begin{tabular}{cc}
\hline$t$ & Circulation time of fresh produce \\
$T$ & The upper limit of the circulation time of fresh produce \\
$C_{0}$ & The price of fresh produce \\
$r$ & Wholesaler bears the percentage of IoT technology adoption costs \\
$A$ & Market size factor of fresh produce \\
$L$ & Processing cost of fresh produce \\
$Y$ & Life cycle of fresh produce \\
$p$ & Retail price of fresh produce \\
\hline
\end{tabular}




\section{Continued}

\begin{tabular}{cc}
\hline$k$ & Price elasticity coefficient of fresh agricultural products \\
$d$ & Market demand for fresh produce \\
$q$ & The order quantity of retailers for fresh produce \\
$W$ & Wholesale price of fresh produce \\
$C^{\text {total }}$ & Total cost of supply chain \\
$R^{\text {total }}$ & Total supply chain revenue \\
\hline
\end{tabular}

\section{2) Decision variables}

\begin{tabular}{|c|c|c|c|c|c|c|}
\hline$C^{i o t}(t)$ & \multicolumn{6}{|c|}{ IoT technology adoption cost } \\
\hline$T C^{\mathrm{w}}(t)$ & \multicolumn{6}{|c|}{$\begin{array}{l}\text { The cost of cold chain logistics transportation of fresh agricultural } \\
\text { products from the place of origin to the wholesaler after time } t\end{array}$} \\
\hline$T C^{r}(t)$ & \multicolumn{6}{|c|}{$\begin{array}{l}\text { Cold chain logistics transportation cost of fresh agricultural } \\
\text { products from wholesalers to retailers after time } t\end{array}$} \\
\hline$S C^{w}(t)$ & \multicolumn{6}{|c|}{$\begin{array}{l}\text { Cold chain logistics storage cost of fresh agricultural products } \\
\text { from the place of origin to the wholesaler after time } t\end{array}$} \\
\hline$S C^{r}(t)$ & \multicolumn{6}{|c|}{$\begin{array}{l}\text { Cold chain logistics storage cost of fresh agricultural } \\
\text { products from wholesalers to retailers after time } t\end{array}$} \\
\hline$\varphi(t)$ & \multicolumn{6}{|c|}{ Preservation rate of fresh agricultural products after time $t$} \\
\hline$\beta(t)$ & \multicolumn{6}{|c|}{ The quality of fresh agricultural products after time $t$} \\
\hline$T C^{f}(t)$ & \multicolumn{6}{|c|}{ Do not adopt the total transportation cost under the Internet of Things technology } \\
\hline$S C^{f}(t)$ & \multicolumn{6}{|c|}{ Do not adopt the total storage cost under the Internet of Things technology } \\
\hline$T C^{\text {iot }}(t)$ & \multicolumn{6}{|c|}{ Adopting total transportation costs under IoT technology } \\
\hline$S C^{i o t}(t)$ & \multicolumn{6}{|c|}{ Adopting total storage costs under IoT technology } \\
\hline$R^{r}(g)$ & \multicolumn{6}{|c|}{ Retailer's income under optimal decision } \\
\hline$R^{w}(g)$ & \multicolumn{6}{|c|}{ Wholesale income under optimal decision } \\
\hline$C^{r}(g)$ & \multicolumn{6}{|c|}{ Retailer's cost under optimal decision } \\
\hline$C^{w}(g)$ & \multicolumn{6}{|c|}{ Cost of wholesaler under optimal decision } \\
\hline \multirow{2}{*}{$\begin{array}{l}\text { Fresh } \\
\text { produce }\end{array}$} & $\begin{array}{l}\text { Transportation cost } \\
\text { Warehousing cost }\end{array}$ & \multirow{2}{*}{ Wholesaler } & $\begin{array}{l}\text { Technical cost } \\
\text { Warehousing cost }\end{array}$ & \multirow{2}{*}{ Retailer } & Retail price & \multirow{2}{*}{ Consumer } \\
\hline & $\begin{array}{l}\text { Product cost } \\
\text { Product loss }\end{array}$ & & $\begin{array}{l}\text { Product cost } \\
\text { Product loss }\end{array}$ & & & \\
\hline
\end{tabular}

Figure 1. One-way flow chart of fresh agricultural product supply chain.

\section{Model Establishment}

Assuming that the wholesaler's share of the IoT adoption cost is $r$, the retailer's share is $(1-r)$ When $r$ is constant, the feasibility of adopting IoT technology is verified by comparing the impact of different IoT adoption costs $C^{\text {iot }}(t)$ on the costs and benefits of wholesalers, retailers, and supply chains; When $C^{\text {iot }}(t)$ is constant, by comparing and analyzing the impact of different $r$ on the cost and benefit of wholesalers, retailers, and supply chains, the optimal value of $r$ is ob- 
tained, and the total return of the supply chain is maximized.

$$
\max \left(R^{\text {total }}-C^{\text {total }}\right)
$$

Assume that the market scale coefficient of fresh agricultural products is $A$, the price elasticity coefficient is $k(k \geq 1)$, the processing cost per unit of fresh agricultural products of the circulation enterprises is $L$, the price per unit of fresh agricultural products is $C_{0}$, and the life cycle is $Y$. The order quantity of the retailer is $q$, the retail price per unit of fresh agricultural products is $p$, the wholesale price is $W$, and the circulation time per unit of fresh agricultural products is $t(0 \leq t \leq T)$.

Warehousing costs are getting higher and higher with time, the wholesaler bears the cold chain logistics storage cost from the place of origin to the wholesaler is $S C^{w}(t)$, the retailer undertakes the cold chain logistics from the wholesaler to the retailer. The storage cost is $S C^{r}(t)$. Suppose the warehousing cost function takes time $t$ as an independent variable, $T$ is a time-limited value, and there are function characteristics:

$$
\frac{\partial S C^{w}(t)}{\partial t} \geq 0,\left(\frac{\partial S C^{w}(t)}{\partial t}\right)^{2}>0, \frac{\partial S C^{r}(t)}{\partial t} \geq 0,\left(\frac{\partial S C^{r}(t)}{\partial t}\right)^{2}>0,0 \leq t \leq T
$$

The transportation cost function is positively related to the distance traveled by the circulation. The longer the distance, the longer the circulation time, the more cold energy consumption and the higher the cost. The wholesaler undertakes the cold chain logistics from the place of origin to the wholesaler. The transportation cost is $T C^{w}(t)$, and the retailer bears the cold chain logistics transportation cost from wholesaler to retailer as $T C^{r}(t)$. Assume that the transportation cost function takes time $t$ as an independent variable and $T$ is a time-limited value. The following functional characteristics exist:

$$
\frac{\partial T C^{w}(t)}{\partial t} \geq 0,\left(\frac{\partial T C^{w}(t)}{\partial t}\right)^{2}>0, \frac{\partial T C^{r}(t)}{\partial t} \geq 0,\left(\frac{\partial T C^{r}(t)}{\partial t}\right)^{2}>0,0 \leq t \leq T
$$

Fresh agricultural products are extremely easy to wear. If the life cycle $Y$ is reached, all agricultural products will be damaged. In order to facilitate research and analysis, the actual quantity change of the product is explained, and the product preservation ratio function $\varphi(t) \quad(0 \leq t \leq T)$, which is closely related to the circulation time $t$, is constructed. When $t=Y, \varphi(t)=0$; When $t=0$, $\varphi(t)=1$. When the decay of fresh agricultural products begins, the decay is slow. As time passes, the decay rate gradually increases, and the following functional characteristics exist:

$$
\frac{\partial \varphi(t)}{\partial t} \leq 0,\left(\frac{\partial \varphi(t)}{\partial t}\right)^{2}<0,0 \leq t \leq Y
$$

When the order quantity is $q$, the wholesaler considers the loss of fresh agricultural products and needs to transport $q / \varphi(t)$ products. And based on the understanding of fresh agricultural products, the quality of fresh agricultural 
products is getting lower and lower with the circulation time $t$, and the quality function of fresh agricultural products is $\beta(t), 0 \leq t \leq T$, when $t=Y$,

$\beta(t)=0$; when $t=0, \beta(t)=1$. Assuming that the quality function is a monotonic continuous decreasing function with respect to the circulation time $t$, and as the circulation time $t$ is accelerated and decremented, the following functional characteristics exist:

$$
\frac{\partial \beta(t)}{\partial t} \leq 0,\left(\frac{\partial \beta(t)}{\partial t}\right)^{2}<0,0 \leq t \leq T
$$

Market demand: The market demand for fresh produce is indicated by $d$, and the higher the quality of the product, the greater the demand, the market demand is expressed as:

$$
d=A p^{-k} \beta(t), 0 \leq t \leq T
$$

If the share ratio of the wholesaler is $r$, then the proportion of the retailer's share is $(1-r)$, then the cost of adopting the Internet of Things shared by the wholesaler is $r \cdot C^{\text {iot }}(t)$, and the transportation cost is $T C^{w}(t)=r \cdot T C^{\text {iot }}(t)$, the storage cost is $S C^{w}(t)=(1-r) \cdot S C^{\text {iot }}(t)$. The adoption cost shared by the retailer is $(1-r) \cdot C^{i o t}(t)$, the transportation cost is $T C^{r}(t)=(1-r) \cdot T C^{i o t}(t)$, and the storage cost is $S C^{r}(t)=r \cdot S C^{\text {iot }}(t)$. In this paper, based on the research of Wang et al. [14], the preservation ratio function of fresh agricultural products is $\varphi(t)=0.9+0.1 \times\left(1-T C^{i o t}(t) / T C^{f}(t)\right)$, the quality function of fresh agricultural products $\beta(t)=0.8+0.2 \times\left(1-T C^{\text {iot }}(t) / T C^{f}(t)\right)$, the circulation time of fresh agricultural products is $t$, in wholesale. When the price is $w$, the retailer's revenue is:

$$
R^{r}(p, q)=\left[p-w-T C^{r}(t)-S C^{r}(t)-L-(1-r) \cdot C^{i o t}(t)\right]
$$

Assuming that the retailer is completely rational, in order to maximize the profit, a suitable retail plan will be formulated according to the actual needs of the market, and the market demand function $d=A p^{-k} \beta(t)$, the retail price of the agricultural product $p=(A \beta(t) / q)^{1 / k}$. Let $M^{r}=T C^{r}(t)+S C^{r}(t)+L+(1-r) C^{\text {iot }}(t)$, bring the $d, p$ equivalents into Equation (2) and get the retailer's income as :

$$
R^{r}(q)=q \cdot\left[\left(\frac{A \beta(t)}{q}\right)^{\frac{1}{k}}-w-M^{r}\right]
$$

Let Equation (3) be derived for $q$, and let the first derivative be 0 , get the retailer order quantity $q$ :

$$
q=A \cdot \beta(t) \cdot\left(\frac{k-1}{k \cdot\left(w+M^{r}\right)}\right)^{k}
$$

Equation (4) into $p=(A \beta(t) / q)^{1 / k}$, the retail price of agricultural products is $p$ : 


$$
p=\frac{k}{k-1} \cdot\left(w+M^{r}\right)
$$

Thus, the cost and benefit of the retailer's optimal decision when the wholesale price given by the wholesaler is $w$.

$$
\begin{aligned}
C^{r}(q) & =q \cdot\left(w+M^{r}\right) \\
& =A \cdot \beta(t) \cdot\left[\frac{k-1}{k \cdot\left(w+M^{r}\right)}\right]^{k} \cdot\left(w+M^{r}\right) \\
& =A \cdot \beta(t) \cdot\left[\frac{k-1}{k}\right]^{k} \cdot\left(w+M^{r}\right)^{-(k-1)} \\
R^{r}(p, q) & =q \cdot\left(p-w-M^{r}\right) \\
& =A \cdot \beta(t) \cdot\left[\frac{k-1}{k \cdot\left(w+M^{r}\right)}\right]^{k} \cdot\left(\frac{w+M^{r}}{k-1}\right)
\end{aligned}
$$

Since the cold chain logistics has physical wear during the circulation process, when the retailer orders $q$ every time, the wholesaler needs to provide a product larger than $q$. The product preservation ratio function $\varphi(t), 0 \leq t \leq Y$, which is closely related to the circulation time, has been constructed above. That is, when the order quantity is $q$, the wholesale market needs to transport $q$ in order to budget the product efficiencies after the product loss $q / \varphi(t)$ production, get:

$$
C^{w}(q)=\left[T C^{w}(t)+S C^{w}(t)+C_{0}+r \cdot C^{i o t}(t)\right] \cdot \frac{q}{\varphi(t)}
$$

Let $M^{w}(q)=T C^{w}(t)+S C^{w}(t)+C_{0}+r \cdot C^{\text {iot }}(t)$, i.e. $M^{w}=r \cdot T C^{i o t}(t)+(1-r) \cdot S C^{i o t}(t)+C_{0}+r \cdot C^{i o t}(t)$, the cost and benefit of the wholesaler are:

$$
\begin{gathered}
C^{w}(q)=M^{w} \cdot \frac{q}{\varphi(t)} \\
R^{w}(q, w)=w \cdot q-C^{w}(q)=w \cdot q-M^{w} \cdot \frac{q}{\varphi(t)}
\end{gathered}
$$

Let Equation (10) be derived for $w$, and let the first derivative be 0 , and know by Equation (3) $\partial R^{w}(q, w) / \partial w=q+w \cdot \partial q / \partial w-M^{w} / \varphi(t) \cdot \partial q / \partial w$, let $\partial R^{w}(q, w) / \partial w=0$, get the wholesale price of wholesaler $W^{*}$ :

$$
W^{*}=\frac{k}{k-1} \cdot\left[\frac{M^{w}}{\varphi(t)}+\frac{M^{r}}{k}\right]
$$

According to the above formula, the wholesale price directly affects the order quantity of retailers. The wholesale price is affected by many factors, including not only the cost of the product itself, but also the transportation and storage costs of wholesalers and retailers, product consumption rate and circulation. A series of costs include simple processing costs. In order to more clearly and intuitively see the impact of wholesale prices on the entire supply chain circulation 
process, the Equation (11) is substituted into the Equation (4), (5), and the retailer order quantity $q$ :

$$
q=A \cdot \beta(t) \cdot\left[\frac{M^{W}}{\varphi(t)}+M^{r}\right]^{-k} \cdot\left(\frac{k-1}{k}\right)^{2 k}
$$

Substituting Equation (11) into Equations (6) and (7) yields the cost and benefit of the retailer:

$$
\begin{gathered}
C^{r}=A \cdot \beta(t) \cdot\left[\frac{M^{W}}{\varphi(t)}+M^{r}\right]^{1-k} \cdot\left(\frac{k-1}{k}\right)^{2 k-1} \\
R^{r}=A \cdot \beta(t) \cdot\left[\frac{M^{W}}{\varphi(t)}+M^{r}\right]^{1-k} \cdot\left(\frac{k-1}{k}\right)^{2 k-1} \cdot\left(\frac{1}{k-1}\right)
\end{gathered}
$$

Substituting the wholesaler's optimal wholesale price Equation (11) and the retailer's optimal order quantity Equation (12) into Equations (13) and (14), the minimum cost of the wholesaler and the wholesaler's optimal income are obtained:

$$
\begin{gathered}
C^{w}(q)=A \cdot \beta(t) \cdot\left[\frac{M^{W}}{\varphi(t)}+M^{r}\right]^{-k} \cdot \frac{M^{W}}{\varphi(t)} \cdot \frac{k-1}{k} \\
R^{w}(q, w)=A \cdot \beta(t) \cdot\left[\frac{M^{W}}{\varphi(t)}+M^{r}\right]^{1-k} \cdot\left(\frac{k-1}{k}\right)^{2 k} \cdot\left(\frac{1}{k-1}\right)
\end{gathered}
$$

Therefore, the total cost of a single cycle of cold chain logistics is:

$$
C^{\text {total }}=C^{r}+C^{w}
$$

The total revenue is:

$$
R^{\text {total }}=R^{r}(g)+R^{w}(g)
$$

\section{Numerical Test}

Using the numerical analysis and optimization methods to analyze the model of the second section, after adopting the Internet of Things technology, the cost of the Internet of Things $C^{\text {iot }}(t)$ for the adoption cost of the Internet of Things is different to the wholesale price, retail price, and order quantity. The average cost and benefit of the retailer, the average cost and benefit of the wholesaler and the impact of the average supply chain cost and return, determine the scientific nature of the adoption of the Internet of Things technology; then analyze the wholesaler and retailer to share the cost of the Internet of Things $r$ to the wholesale price, retail prices, order quantities, retailers' costs and benefits, wholesalers' costs and benefits, the impact of total supply chain returns, get the optimal solution for $r$, and maximize the total return of the entire cold chain logistics.

\subsection{Study Setting}

In order to facilitate our work on the analysis of the case study after adopting the 
Internet of Things technology, we first give a basic data value as a reference. $C_{0}=0.8$ yuan $/ \mathrm{kg}$, demand scale $A=900000 \mathrm{~kg}$, demand elasticity $k=2$, preservation ratio function of fresh agricultural products in initial circulation $\varphi(t)=0.95$, circulation enterprises. The processing cost of each fresh produce is $L=0.9$ yuan $/ \mathrm{kg}, \quad r=0.5, C^{\text {iot }}(t)=1.0, T C^{f}(t)=1.0, S C^{f}(t)=0.7$.

Then adopt the total transportation cost of Internet of Things technology $T C^{\text {iot }}(t)=T C^{f}(t)-0.1 \times C^{\text {iot }}(t)=1.0-0.1=0.9$ yuan $/ \mathrm{kg}$; total storage under the Internet of Things technology Cost

$S C^{\text {iot }}(t)=S C^{f}(t)-0.1 \times C^{\text {iot }}(t)=0.7-0.1=0.6 \quad$ yuan $/ \mathrm{kg} ; \quad$ the preservation function of fresh agricultural products $\varphi(t)=0.9+0.1 \times\left[1-T C^{\text {iot }}(t) / T C^{f}(t)\right]$; quality function of fresh agricultural products $\beta(t)=0.8+0.2 \times\left[1-T C^{\text {iot }}(t) / T C^{f}(t)\right]$.

Substituting the values of the above formula into the model of the second section, we obtain: $M^{w}=1.5+0.3 r+(r-0.1) C^{\text {iot }}, M^{r}=1.2+0.3 r+(0.9-r) C^{\text {iot }}$, when $r=0.5, C^{i o t}(t)=1.0, M^{w}=2.05, M^{r}=1.75$, wholesale price, retail price, order quantity, retailer's cost and benefit, wholesaler's cost and benefit, supply. The total cost of the chain and total revenue, as well as the average cost and benefit of the retailer, the average cost and benefit of the wholesaler, and the average total cost and return of the supply chain are shown in Table 1.

\subsection{Calculation of Results}

1) The influence of $C^{\text {iot }}(t)$ on the logistics decision of fresh produce

Let $r=0.5, C^{\text {iot }}(t)$ take $0,0.1,0.5,1,1.5,2,2.5,3,4$ respectively, observe the difference in the cost of adoption of the Internet of Things to wholesale price, retail price, order quantity, retailer. The average cost and benefit, the average cost and income of the wholesaler and the average supply chain cost and return, calculate the values shown in Table 2. Figure 2 shows the impact of the Internet of Things adoption cost $C^{\text {iot }}(t)$ on wholesale prices and retail prices. Figure 3 shows the impact of the IoT adoption cost $C^{\text {iot }}(t)$ on the order quantity. Figure 4 shows the impact of the IoT adoption cost $C^{\text {iot }}(t)$ on the average cost of wholesalers and the average cost of retailers. Figure 5 shows the impact of IoT adoption cost $C^{\text {iot }}(t)$ on the average income of wholesalers and the average income of retailers. Figure 6 shows $C^{\text {iot }}(t)$. The impact on the average cost and benefits of the supply chain.

As can be seen from the figure, after adopting the Internet of Things technology, the wholesale price and retail price increase with the increase of the cost of adopting the Internet of Things. The retailer's response is more sensitive, the increase is faster, and the overall trend of the function is changed. The increase of $C^{\text {iot }}(t)$ decreases rapidly first, then slowly decreases, showing the trend of quadratic concave function; since wholesalers and retailers share the cost of adopting IoT, the average cost of wholesalers and retailers gradually. The increase trend of retailers is more obvious. Although the average cost of wholesalers and retailers has increased, the adoption of IoT technology has greatly improved the quality and storage time of products, so the average income of wholesalers and 
retailers has shown an upward trend. The trend of change in business is more obvious. The data proves that adopting IoT technology plays a positive role for wholesalers and retailers, so adopting IoT technology is scientific.

Table 1. Cold chain logistics decision value when $r=0.5, C^{\text {iot }}(t)=1.0$.

\begin{tabular}{cc}
\hline Parameter & Decision value \\
\hline$w$ & 5.9995 \\
$q$ & 14.811 \\
$A C^{r}(g)$ & 3364.20 \\
$A C^{w}(g)$ & 7.4055 \\
$A R^{r}(g)$ & 7.4055 \\
$A R^{w}(g)$ & 2.2527 \\
$A C^{\text {total }}$ & 3.7027 \\
$A R^{\text {total }}$ & 9.6582 \\
\end{tabular}

Table 2. The impact of $C^{\text {iot }}(t)$ on logistics decision-making.

\begin{tabular}{cccccccccc}
\hline \multirow{2}{*}{ Parameter } & \multicolumn{8}{c}{ When the decision value is $C^{\text {iot }}(t)=1.0$} \\
\cline { 2 - 10 } & 0.0 & 0.1 & 0.5 & 1.0 & 1.5 & 2.0 & 2.5 & 3.0 & 4.0 \\
\hline$w$ & 4.5333 & 4.8414 & 5.3384 & 5.9555 & 6.5680 & 7.1761 & 7.7797 & 8.3790 & 9.5649 \\
$p$ & 11.4667 & 11.8628 & 13.1768 & 14.8110 & 16.4361 & 18.0522 & 19.6595 & 21.2581 & 24.4298 \\
$q$ & 5475.90 & 5129.10 & 4198.60 & 3364.20 & 2765.20 & 2319.90 & 1979.30 & 1712.70 & 1327.00 \\
$A C^{r}(g)$ & 5.7333 & 5.9314 & 6.5884 & 7.4055 & 8.2180 & 9.0261 & 9.8297 & 10.6290 & 12.2149 \\
$A C^{w}(g)$ & 1.6667 & 1.8757 & 2.0442 & 2.2527 & 2.4590 & 2.6630 & 2.8649 & 3.0645 & 3.4574 \\
$A R^{r}(g)$ & 5.7333 & 5.9314 & 6.5884 & 7.4055 & 8.2180 & 9.0261 & 9.8297 & 10.6290 & 12.2149 \\
$A R^{w}(g)$ & 2.8667 & 2.9657 & 3.2942 & 3.7027 & 4.1090 & 4.5130 & 4.9149 & 5.3145 & 6.1074 \\
$A C^{\text {total }}$ & 7.4000 & 7.8071 & 8.6326 & 9.6582 & 10.6770 & 11.6891 & 12.6946 & 13.6935 & 15.6723 \\
$A R^{\text {total }}$ & 8.6000 & 8.8971 & 9.8826 & 11.1082 & 12.3270 & 13.5391 & 14.7446 & 15.9435 & 18.3223 \\
\hline
\end{tabular}

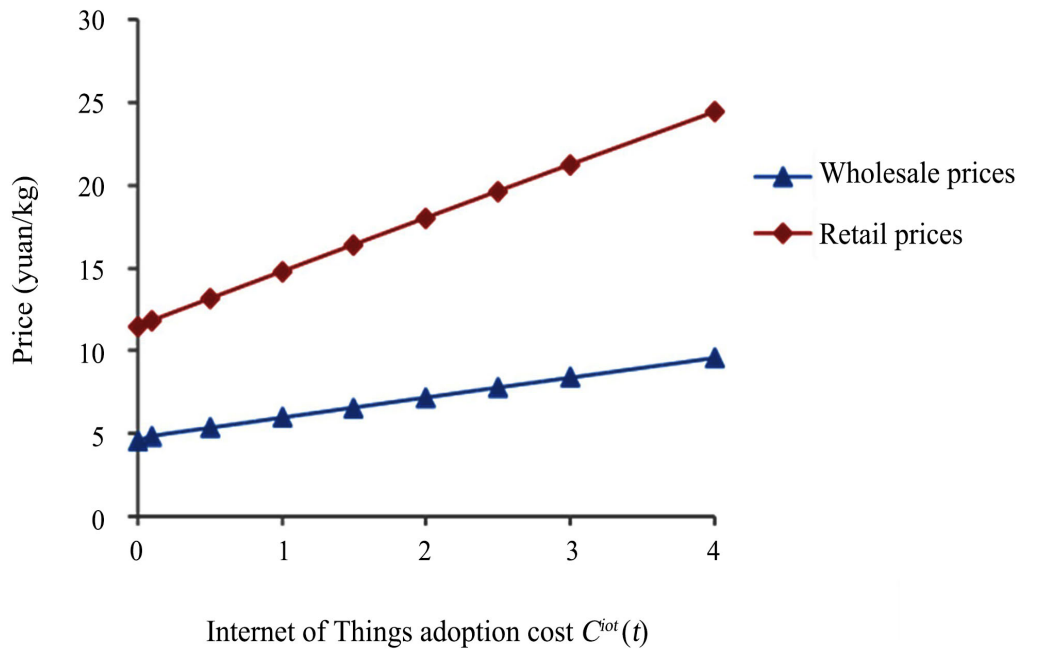

Figure 2. The impact of $C^{\text {iot }}(t)$ on wholesale prices and retail prices. 


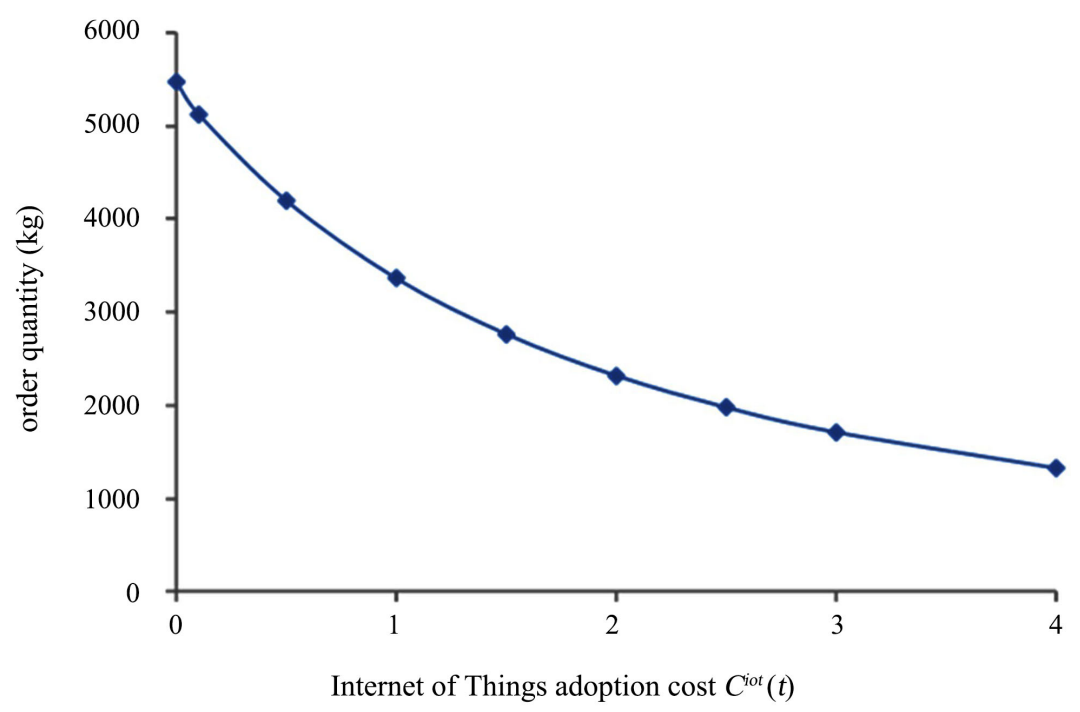

Figure 3. The impact of $C^{\text {iot }}(t)$ on the order quantity.

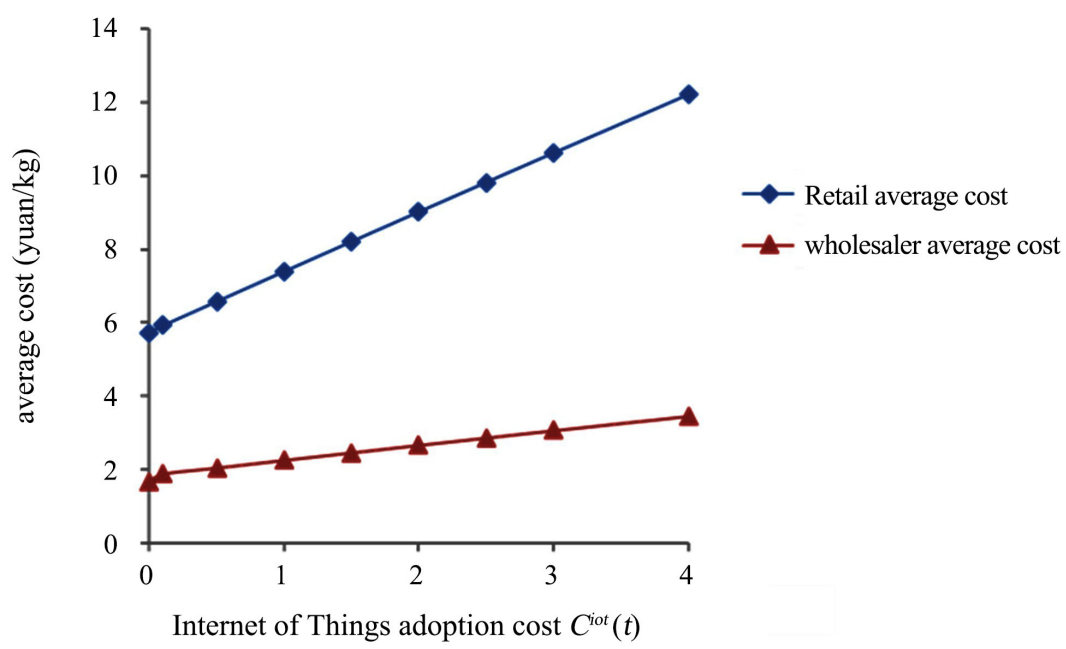

Figure 4. The impact of $C^{\text {iot }}(t)$ on the average cost of wholesalers and retailers.

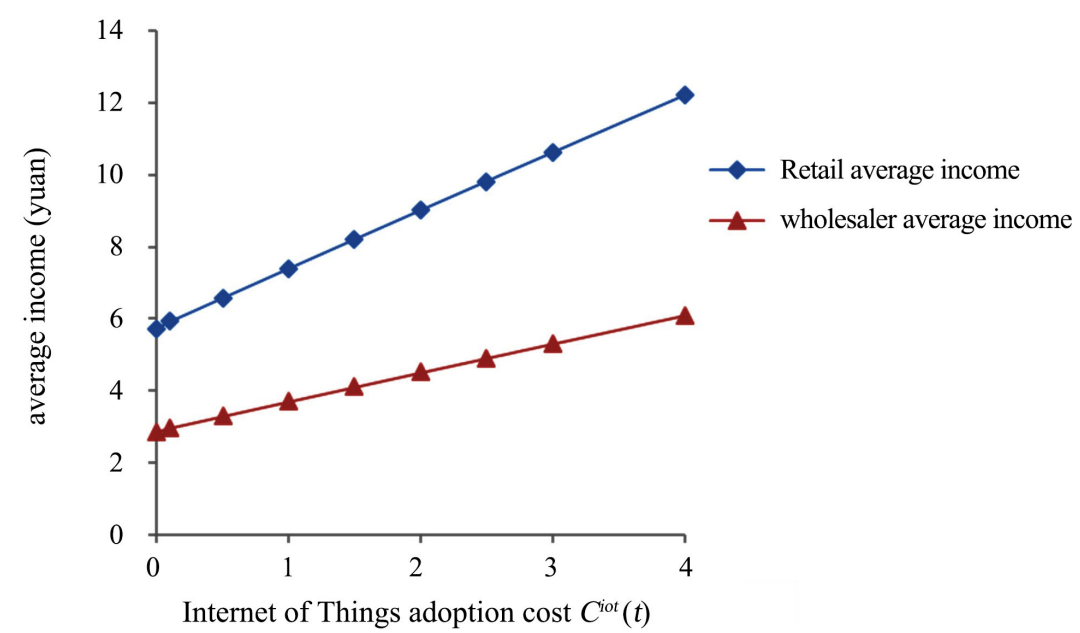

Figure 5. The impact of $C^{\text {iot }}(t)$ on the average income of wholesalers and retailers. 


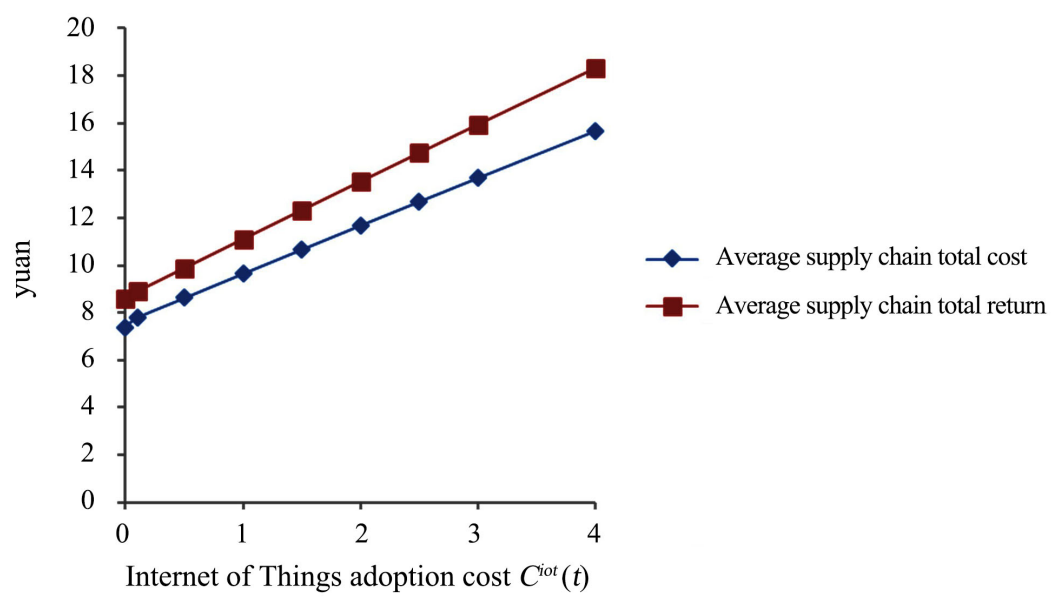

Figure 6. The impact of $C^{\text {iot }}(t)$ on the average cost and benefit of the supply chain.

2) The influence of $r$ on the logistics decision of fresh produce

Let $C^{\text {iot }}(t)=1.0, r$ take $0,0.2,0.4,0.6,0.8,1.0$ respectively, observe the difference $r$ between wholesaler and retailer's share of wholesale price, retail price, order quantity, retailer's cost and income, wholesaler's cost and return, and total supply chain impact. Calculate the values as shown in Table 3. Figure 7 shows the effect of $r$ on the wholesale price and retail price. Figure 8 shows the effect of $r$ on the order quantity. Figure 9 shows the effect of $r$ on the wholesaler's cost and return. Figure 10 shows the effect of $r$ on the retailer's cost and return. Figure 11 is the impact of $r$ on the total return of the supply chain.

As can be seen from the figure, after adopting the Internet of Things technology, the wholesale price and retail price increase with the increase of $r$, the wholesaler's reaction is more sensitive, the increase is faster, and the overall trend of the function is changed; the order quantity increases with $r$. And the overall trend shows a trend of change; the wholesaler's income is very insensitive to the change of $r$, almost showing a trend of 0 change, the cost of wholesalers increases with the increase of $r$, retailer costs and benefits with $r$. The increase and decrease, the overall trend of the function is presented once, and the two curves coincide. According to Equations (13) and (14), when $k=2$, the retailer cost and return formula are the same, so the two curves coincide. Finally, the total return of the supply chain decreases with the increase of $r$, and the overall trend of a function appears. When the total return of the supply chain is the largest, $r$ takes the optimal value. So the results show that $r=0$, that is, the retailer shares all the cost of adoption of the Internet of Things.

\section{Conclusions}

This paper adopts the cost-benefit perspective to adopt the logistics decision-making optimization problem of IoT technology in the cold chain logistics of fresh produce, and analyzes the average cost and income of the wholesalers and retailers by using the analytical model to analyze the cold chain logistics of fresh produce, the impact of logistics decisions, and then the use of numerical analysis methods to 
share the proportion of the cost of adoption of IoT between wholesalers and retailers.

Table 3. The impact of $r$ on logistics decision-making.

\begin{tabular}{ccccccc}
\hline \multirow{2}{*}{ Parameter } & \multicolumn{5}{c}{ When the decision value is $r=0.5$} \\
\cline { 2 - 7 } & 0.0 & 0.2 & 0.4 & 0.6 & 0.8 & 1.0 \\
\hline$w$ & 5.1769 & 5.4884 & 5.7998 & 6.1112 & 6.4226 & 6.7341 \\
$p$ & 14.5538 & 14.6567 & 14.7596 & 14.8624 & 14.9653 & 15.0681 \\
$q$ & 3484.20 & 3435.50 & 3387.70 & 3341.00 & 3295.20 & 3250.40 \\
$A C^{r}(g)$ & 25354.00 & 25176.00 & 25001.00 & 24828.00 & 24657.00 & 24489.00 \\
$A C^{w}(g)$ & 5360.30 & 6266.90 & 7147.70 & 8003.70 & 8835.60 & 9644.10 \\
$A R^{r}(g)$ & 25354.00 & 25176.00 & 25001.00 & 24828.00 & 24657.00 & 24489.00 \\
$A R^{w}(g)$ & 12677.00 & 12588.00 & 12500.00 & 12414.00 & 12329.00 & 12244.00 \\
$A R^{\text {total }}$ & 38031.00 & 37764.00 & 37501.00 & 37242.00 & 36986.00 & 36733.00 \\
\hline
\end{tabular}

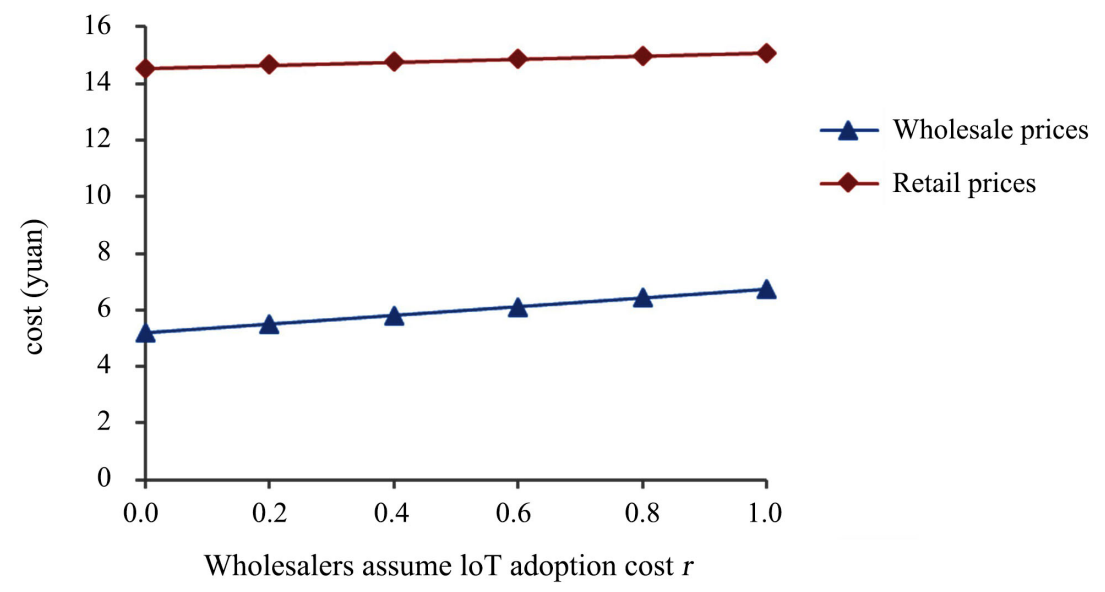

Figure 7. The impact of $r$ on wholesale prices and retail prices.

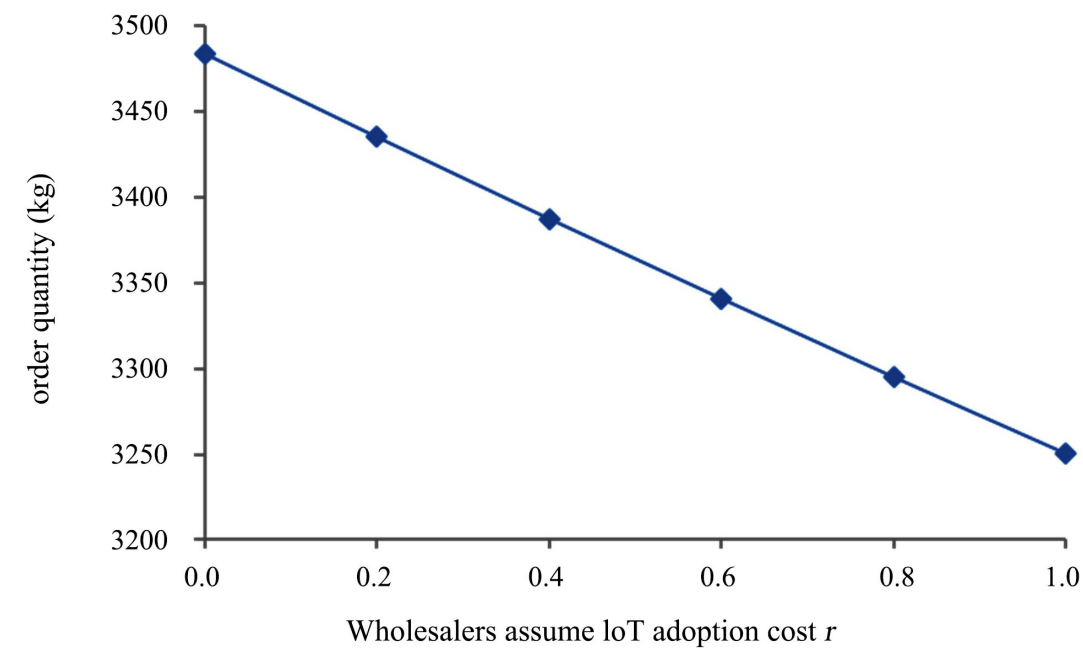

Figure 8. The impact of $r$ on the order quantity. 


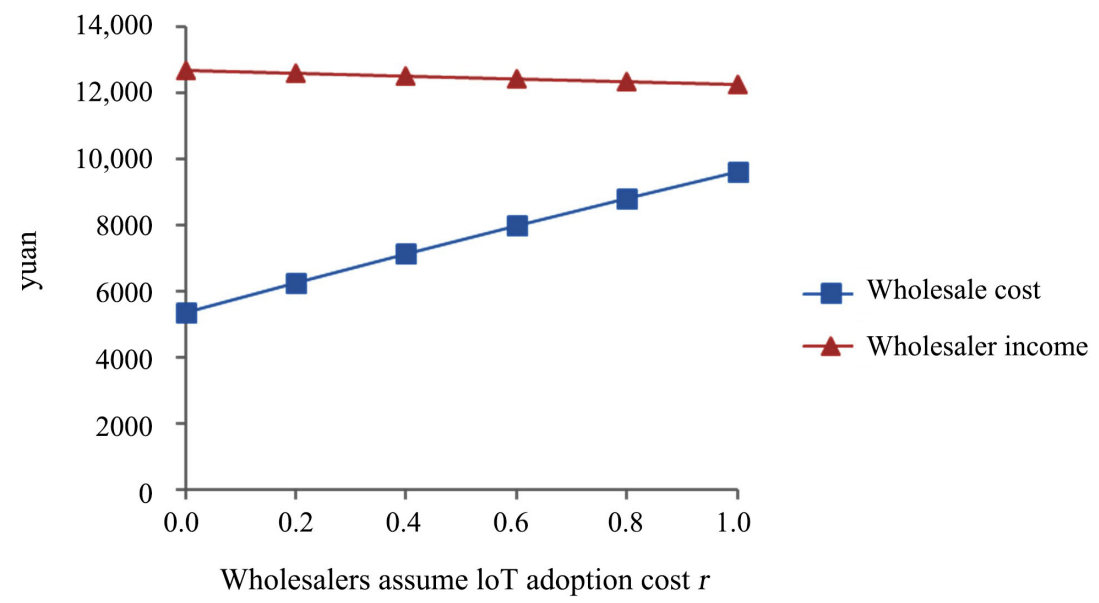

Figure 9. The impact of $r$ on the average cost of wholesalers and retailers.

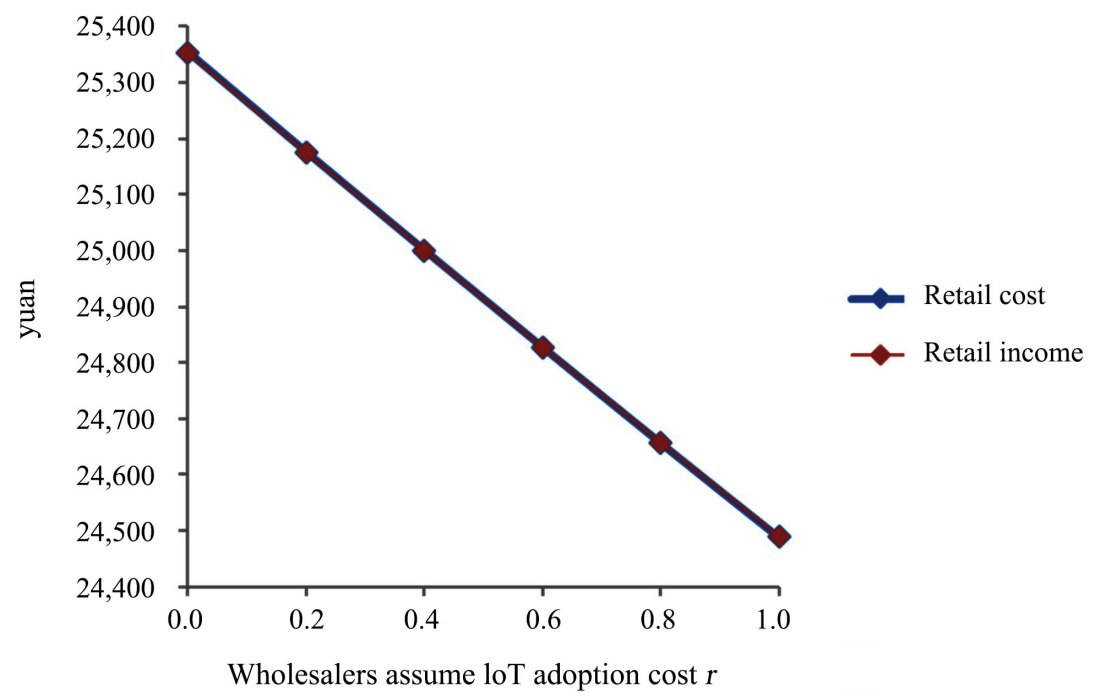

Figure 10. The impact of $r$ on the average income of wholesalers and retailers.

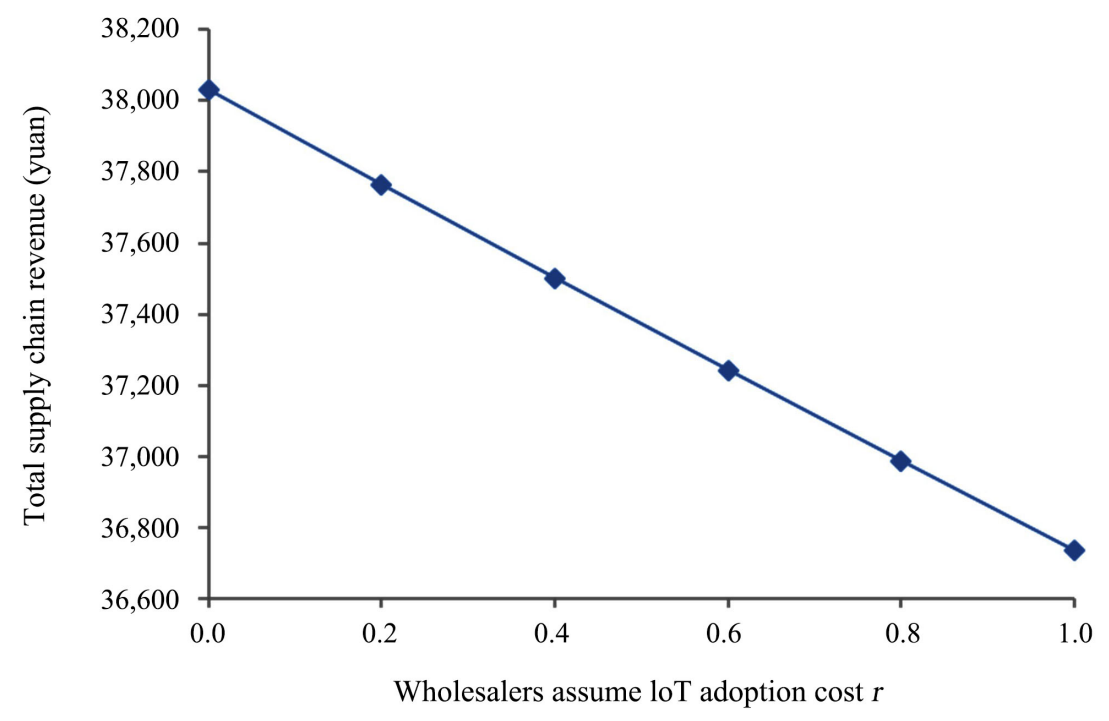

Figure 11. The impact of $r$ on the average cost and benefit of the supply chain. 
The research results show that the application of IoT technology to cold chain logistics can increase the average supply chain total revenue, and has a positive effect on cold chain logistics. When retailers share all IoT adoption costs, the total supply chain revenue is the largest. In this regard, each cold chain logistics enterprise can consider the application of Internet of Things technology in the specific operation process, thereby generating greater profits.

Considering the practicability and feasibility of the conclusion, in the future research, we can consider the ratio of the adoption cost of the Internet of Things when the retailer adopts the pricing strategy and transfers some prices to the supply chain entities at all levels. In the future research, we can also consider expanding the range of $r$ values, further verifying the development trend of each decision value, and making the research results more scientific. In addition, the discussion of the changes in the quality of agricultural products caused by the adoption of Internet of Things technology, the introduction of discount strategies to control retail prices, and the construction of flexible and accurate replenishment, and ordering model are also important research directions.

\section{Conflicts of Interest}

The author declares no conflicts of interest regarding the publication of this paper.

\section{References}

[1] Shabani, A., Saen, R.F. and Torabipour, S.M.R. (2012) A New Benchmarking Approach in Cold Chain. Applied Mathematical Modelling, 36, 212-224. https://doi.org/10.1016/j.apm.2011.05.051

[2] Wang, S.Y., Tao, F.M. and Shi, Y.H. (2018) Optimization of Location-Routing Problem for Cold Chain Logistics considering Carbon Footprint. International Journal of Environmental Research and Public Health, 15, 86. https://doi.org/10.3390/ijerph15010086

[3] Jing, W., Liu, H.T. and Zhao, R. (2018) The Optimization of Cold Chain Operation Based on Fresh Food Safety. Systems Engineering-Theory \& Practice, 38, 122-134.

[4] Mejjaouli, S. and Babiceanu, R.F. (2018) Cold Supply Chain Logistics: System Optimization for Real-Time Rerouting Transportation Solutions. Computers in Industry, 95, 68-80. https://doi.org/10.1016/j.compind.2017.12.006

[5] Wang, X.B. (2017) Keep the Products Fresh: A QFD Approach to Improve the Logistics Service Quality of Cold Chain. International Conference on Logistics, Informatics and Service Science, Sydney, 24-27 July 2016.

[6] Zhang, Y., Cheng, R.Q., Chen, S.H., Eguchi, K. and Chen, T. (2018) Design of Fresh Food Sensory Perceptual System for Cold Chain Logistics. ITM Web of Conferences. https://doi.org/10.1051/itmconf/20181703017

[7] Yong, W., Zhang, P.L. and Lu, Q. (2017) Collaboration Research on Fresh Production Supply Chain Information System. International Conference on Logistics, Informatics and Service Sciences, Sydney, 24-27 July 2016.

[8] Kang, Y.S., Jin, H., Ryou, O. and Lee, Y.H. (2012) A Simulation Approach for Optimal Design of RFID Sensor Tag-Based Cold Chain Systems. Journal of Food Engineering, 113, 1-10. https://doi.org/10.1016/j.jfoodeng.2012.05.036 
[9] Yang, L., Zhang, H.Y. and Tang, S.Z. (2015) Rfid Technology Application on the Supervision of Cold-Chain Logistics Warehousing. Advanced Graphic Communications, Packaging Technology and Materials, 369, 619-626.

https://doi.org/10.1007/978-981-10-0072-0_77

[10] Tanner, D. (2016) Applications for RFID Technologies in the Food Supply Chain. Reference Module in Food Science. https://doi.org/10.1016/B978-0-08-100596-5.03164-4

[11] Wongpatikaseree, K., Kanka, P. and Ratikan, A. (2018) Developing Smart Farm and Traceability System for Agricultural Products using IoT Technology. IEEE 2018 IEEE/ACIS 17 th International Conference on Computer and Information Science (ICIS), Singapore, 6-8 June 2018, 180-184.

[12] Lu, S. and Wang, X. (2017) Toward an Intelligent Solution for Perishable Food Cold Chain Management. 7 th IEEE International Conference on Software Engineering and Service Science, Beijing, 26-28 August 2016.

[13] Salunkhe, P.G. and Nerkar, R. (2017) IoT Driven Smart System for Best Cold Chain Application. International Conference on Global Trends in Signal Processing, Information Computing and Communication, Jalgaon, 22-24 December 2016.

[14] Wang, X.H. and Zhang, Q.L. (2016) Construction of Cold-Chain Logistics System for Fresh Agricultural Products Based on the Internet of Things: Framework, Mechanism and Path. Journal of Nanjing Agricultural University (Social Sciences Edition), 2016, 31-41. 